\title{
Housing quality, Permitted Development and the role of regulation after COVID-19
}

The ongoing COVID-19 pandemic has brought the issue of housing quality into sharp relief. For many people, home before the pandemic was a place to return to after work, school or a holiday: one of a number of spaces in which life is played out. But COVID-19 has focused daily existence on the home. It has suddenly become more intensely multi-functional: a workspace, a classroom and a leisure space all bundled into one (it was always these things, but never to the exclusion of everywhere else). This situation will not last, but individuals' and households' perceptions of the required utility of home may have changed irrevocably.

Housing quality, and how to support and achieve that quality, is a perennial debate in planning and housing circles. Regulation and good design feature as answers or antidotes to the worst crimes of largely unfettered speculative development in the UK, the most heinous of which have often been committed by developers of the conversions of commercial buildings to residential use, under deregulated permitted development rights (PDR) in England. In this viewpoint, we bring together past research on regulation and design innovation to provide a brief commentary on likely future debates in this area.

\section{Housing quality and regulation}

Regulation does not always guarantee quality (see, for example, Carmona et al, 2020), but it can do two important things that contribute to the overall quality of housing: first, it can prevent really bad housing from being built. To do that, it needs to set minimum thresholds that are grounded in an understanding of the utility minimums that housing needs to achieve. In the UK, Parker Morris did that by carefully reviewing the changing use and function of housing in the 1950s (MHLG, 1961). It translated (or reduced) a qualitative view of utility into a quantitative set of prescriptions on floor space and storage. Second, it can provide a framework for good design. Arguably, the 'Parker Morris Standards' were overly prescriptive (like the Tudor Walters standards and Housing Manuals that they succeeded: see Gallent et al, 2010) and locked the UK into the mind-set that housing standards are fixed and encourage pattern-book interpretation - and therefore monotony in residential typology. But regulation with a degree of flexibility, which bends to allow different interpretation, can achieve the twin goals of preventing housing horrors and supporting design innovation.

Minimum standards for housing design are set across Europe, and Italy seems to provide a good example of flexible regulation, where the standards - fixed minimums devised in 1896 and updated in 1975 (see Gallent et al, 2010) - relate floor space to occupation whilst allowing varying distributions of space between living rooms and bedrooms. They are also concerned with air circulation and light, keeping health goals in sight. Windows need to be in proportion to rooms and ceiling heights need to be sufficient to allow air movement. All of these things can be reinterpreted, to some extent, for historic conversions or housing on constrained sites, allowing the designer a degree of freedom to meet obligations in creative ways. But absolute benchmarks remain.

Past research on the Italian experience of regulation looked not only at the balance between flexibility and prescription in the regulatory framework but also at key lessons - regulatory outcomes that work with good design principles (Gallent et al, 2010; Madeddu et al, 2015). These include having the right kind of outdoor space - an issue that has suddenly rocketed up the design agenda in 
light of the COVID-19 lockdown. Small balconies overlooking busy roads, for example, are of little value. Proximity to roads means that balconies need to face away, usually into a central courtyard (that research focused on Turin, where such internal courtyards - big open spaces and not narrow light-wells - are a common typological feature). Consideration of appropriate external space is a key aspect of typology, and one that is likely to become more important in housing quality debates in the years ahead. Recent lockdown restrictions in Italy have been far stricter than in the UK. Exercise more than 200 meters from home was barred after the 25 March, making it impossible for most people to access parks and other open spaces. For that reason, the utility of homes and access to space is a debate that is also likely to intensify in Italy - but in the context of a well-established approach to housing standards, which can also be adapted for particular cities and their urban contexts.

The research also revealed a meeting of minds, between regulators and private market actors, on the value of regulation. 'Private enterprise cannot be left to care for social issues' was the assertion of a private housebuilder in Turin: whilst regulation was viewed as a 'weapon' against the worst excesses of speculation by one local authority officer. Moreover, housebuilders argued that regulatory standards created a level playing field for business, preventing incursions by unscrupulous developers seeking to exploit housing shortages (of the type seemingly welcomed by the UK Government, to the consternation of planners and even developers, many of whom would welcome a level playing field in England rather than the race to the bottom that PDR has triggered). In Turin, planning was viewed as providing the 'leadership' needed to guide the response to those shortages, setting the game rules and giving trusted companies the opportunity to be partners in housing delivery.

Not everything was rosy: regulation was also seen (positively rather than pejoratively) as a means of excluding new market actors and protecting existing business interests. There is of course a bigger story here of market processes and competition, but on the issue of housing standards, a broad narrative had been agreed. Even estate agents noted the value of space regulation: it simply reduced the risk of buyers recoiling at kitchen or bedroom space when viewing an apartment. Italian standards give them a clear sense of what to expect when house-hunting. But a word of caution: the Italian standards are sometimes deployed inflexibly because local discretion (and interpretation) allows city administrations to ratchet up requirements over time. There is a Fabian tendency in some Italian authorities to regulate for every eventuality, prescribing the exact configuration of spaces and fixing standards for bathrooms and antibagni (the spaces between bathrooms and living spaces - 'exasperating regulations for individual rooms'), which can sometimes make compliance difficult, especially in conversions. 'Nothing can comply with them' is a regular complaint amongst architects who, whilst supporting the aims of space standards, look for the 'wriggle room' needed to design solutions for awkward and difficult spaces. Not all contexts can support the same typological outcomes or the same internal configurations, but rather than trying to circumvent standards, the argument amongst Italian architects is that designers need to have a place at the table when those standards are designed or amended so as to leave room for design-led innovation. A similar argument has been heard recently in the UK's Urban Design Group: 'Long life, loose fit' is a mantra that seeks to assert the link between regulatory frameworks and design (Evans, 2020) 
Had the Italian standards applied in England, it would not have been possible to carve homes from some of the offices subject to PDR, irrespective of the creative input of designers; and in most other converted buildings, the final scheme designs would have looked very different. Some of the schemes should never have gone ahead at all; others should have been carefully rethought within the context of flexible regulation, and only gone ahead with significant design innovation. But the unwritten mantra of PDR has been 'quick, cheap and dirty', with no input from planners on questions of design. Analysis of PDR outcomes in England reveal three things. First, a majority of the 65,000 units created from office-to-residential conversion under PDR since 2013 deliver grossly inadequate living space; second, they almost always lack the balconies or outdoor spaces (private and communal) that are regularly, and increasingly, a feature of permissioned schemes; and third, they are often blighted by a lack of natural light (Clifford et al, 2018; Clifford et al, 2019; Clifford, 2019).

Advice concerning outdoor space is regularly included in supplementary planning guidance, especially in London where this issue often taxes planning teams trying to develop policies and solutions for relatively dense urban schemes (Mayor of London, 2016). Natural light - a key concern of Italian regulation - is simply not deliverable in some converted offices and in its place, atriums are frequently used as 'light wells' with the worst-positioned residential units simply overlooking these internal spaces. There is a clear case for far tighter regulation of PDR schemes - regulation that perhaps acknowledges the unique design challenge they pose. Regulation imposes cost, as does design innovation. In a good scheme, that cost will be shared by the landowner, the developer and the occupant. But a lack of regulation in bad schemes, including the many that have sprung up in England, generate their own costs which are borne by the occupant alone: not a monetary cost but one paid for in anxiety, poor health and low utility. Indeed, there is a long-established link between poor housing quality and poor physical and mental health of occupiers (for example WHO, 2018). Housing quality, achieved through a mix of regulation and design innovation, must be measured in the housing services provided, which have been extremely limited in many PDR schemes.

\section{COVID-19, the housing market and general housing quality}

The COVID-19 crisis has shone a new light on these worst offences against housing quality and liveability. The experience of being housebound for a prolonged period - and the risk of it all happening again in the next year - may have a lasting impact on residential choice and has perhaps shifted the benchmark of acceptability for internal and external space in new housing. It will not be long before the impact on choice is known. At the time of writing, estate agents have shut up shop and property viewings are suspended. The volume of sale transactions has plummeted. Once people start thinking about buying homes again, the shift in preferences will become clear. And data on residential sales will speak to a broader set of expectations, across all segments of the market and all tenures. Research in Italy after the 2009 Global Financial Crisis revealed a turn away from small flats with limited external space, not because of any personal experience but because of a perception of falling utility and asset value (Gallent et al, 2010).

A turn away from lower standard housing now, after the COVID-19 crisis, will be driven not only by owner-occupiers' perceptions of low utility (can I live there if we face this situation again? Will my children have space to study and play? Will I be able to work from home?), but also by perceptions of the saleability and rentability of poorly-designed units. If market behaviour pushes for higher 
quality - and if there is a 'flight to quality' reflected in transaction volumes and prices - it becomes increasingly difficult to justify both PDR per se (as an ignored sector, where any consideration of good design is simply jettisoned) and the wider lack of regulation across the housing sector. Many people living in poor quality PDR conversions are not there through choice but because of desperate housing need, with the worse quality homes being either private rental or temporary housing. This is likely to remain the case post-COVID, however the government's response may change. There is an emergent 'equalities' and 'levelling up' agenda in housing: really bad housing - now represented by PDR - is likely to be a constant embarrassment to politicians talking up that agenda, especially if further research draws links between PDR, poor health and propensity to succumb to COVID-19, or if workers in the foundational economy - healthcare, public services and retail - are over-represented in that sector or at least find themselves more often in poor quality private rented housing. In the case of Parker Morris, of course, the standards only applied to public housing, but this ensured an acceptable minimum quality for the most vulnerable in society and also, it has been suggested, set a benchmark for housing developed by the private sector (Manoocheheri, 2009). The truth is that commercial buildings will seldom achieve the 'gold standard' in housing design: meaningful standards would simply prevent many PDR schemes from progress. This would be a good outcome.

\section{Future pathways for housing quality and PDR}

PDR is a neoliberal response to housing crisis: getting 'homes' built at any cost (and mainly a cost borne those unfortunate enough to find themselves in PDR units). Park (2017: 45) has observed that government's preference for 'described' housing standards, which planning authorities can adopt into their local plans (a take-it-or-leave it approach that is regularly over-powered by viability testing), was 'motivated by a political desire to boost house building, and therefore the economy as a whole'. It was a lacklustre nod to quality advocates. PDR - the worst quality offender - has always faced fierce criticism from lobby and interest groups who argue that quality and liveability in housing cannot be sacrificed in pursuit of a delivery target and that 'home' has to deliver against health, wellbeing and social equity goals.

Those voices will become louder in the post-COVID-19 world, seeing PDR housing as a last remnant (we hope) of a discredited approach to housing delivery that lacks all empathy for people and attaches no value to their aspirations. But, with the potential for higher vacancy rates in the office and commercial sectors post-pandemic, there is a real chance we might see yet more housing created through PDR, unless there is a change in policy in response to such voices. It might be possible to integrate design standards into our more fixed building control regulations, but as the evidence from Italy shows, a more flexible regulatory approach may be desirable. Here, there is an argument that the traditional British approach to planning control can offer safeguards against extremes of poor quality whilst still allowing some flexibility for good design: described standards with minimum quality thresholds might yet work if developers are denied the chance to sidestep them because of dubious viability claims (if it is evidentially impossible to build good housing on a site then either alternative sites must be found or, more realistically, the cost of regulation must be factored into the price paid for land). Ensuring that all development is subject to thorough planning scrutiny, whilst equipping local authorities with the framework (of standards) and resources to make meaningful design judgements, will be vitally important in post-COVID England. The legitimate role of regulation, in that context, will inevitably be to ensure that appallingly poor-quality schemes do not go ahead; and that when good housing is delivered, it adds value to people's lives. 


\section{References}

CARMONA, M., ALWAREA, A., GIORDANO, V., GUSSEINOVA, A. and OLALEYE, F. (2020) 'A housing design audit for England', https://indd.adobe.com/view/23366ae1-8f97-455d-896a-1a9934689cd8 (accessed 11.05.20)

CLIFFORD, B. (2019) Healthy Homes? Thirty Examples of Permitted Development Conversions, https://www.ucl.ac.uk/bartlett/planning/sites/bartlett/files/tcpa room the breathe examples clifford et al.pdf (accessed 11.05.20)

CLIFFORD, B., FERM, J., LIVINGSTONE, N. and CANELAS, P. (2018) Assessing the impacts of extending Permitted Development Rights to office-to-residential change of use in England. Report to the RICS Research Trust. London, RICS

CLIFFORD, B., FERM, J., LIVINGSTONE, N. and CANELAS, P. (2019) Understanding the Impacts of Deregulation in Planning: Turning Offices into Homes? Palgrave Pivot, London.

EVANS, R. (2020) New Lives, New Values [Webinar], http://www.udg.org.uk/events (accessed 05.05.2020)

GALLENT, N., MADEDDU, M. and MACE, A. (2010) 'Internal housing space standards in Italy and England', Progress in Planning, 74(1), 1-52

MADEDDU, M., GALLENT, N. and MACE, A. (2015) 'Space in new homes: delivering functionality and liveability through regulation or design innovation?' Town Planning review, 86(1), 73-95

MANOOCHERI, J. (2009) Social Policy and Housing: Reflections of Social Values. PhD Thesis. London, University College London

MAYOR OF LONDON (2016) 'Housing: Supplementary Planning Guidance', https://www.london.gov.uk/sites/default/files/housing spg final.pdf (accessed 11.05.20)

MHLG - MINISTRY OF HOUSING AND LOCAL GOVERNMENT (1961) Homes for Today and Tomorrow (Report of the Parker Morris Committee). London: HMSO.

PARK, J. (2017) One hundred years of housing space standards. What now? http://housingspacestandards.co.uk/assets/space-standards onscreen.pdf (accessed 05.05.20)

WHO (2018) 'WHO Housing and health guidelines', https://www.who.int/publications-detail/whohousing-and-health-guidelines (accessed 11.05.20) 